\title{
Effect of temperature dependent viscosity on biomag- netic fluid flow and heat transfer over a nonlinear stretching sheet
}

\author{
Md. Jahangir Alam ${ }^{1}$, Md. Ghulam Murtaza ${ }^{2 *}$ \\ ${ }^{1,2}$ Department of Mathematics, Comilla University, Comilla, Bangladesh
}

\author{
Keywords \\ Biomagnetic fluid \\ Magnetic dipole \\ Nonlinear stretching sheet \\ Ferrohydrodynamics (FHD) \\ Magnetohydrodynamics (MHD) \\ Viscosity as a function \\ Temperature \\ Radiation
}

Received: 6 September 2019

Accepted: 7 November 2019

Published: 12 February 2020

\begin{abstract}
This investigated the flow and heat transfer of two-dimensional biomagnetic fluid (blood) flow over a non-linear stretching sheet in the presence of magnetic dipole. It is assumed that the magnetic field is sufficiently strong enough to saturate the ferrofluid, and a linear function of temperature difference can approximate variation of magnetization with temperature. The fluid viscosity is assumed to vary as an inverse linear function of the temperature. The governing boundary layer equations with boundary conditions are simplified to a couple of higherorder equations using the usual transformation. Numerical solutions are obtained by using the bvp4c function technique in MATLAB software. The acquired results are shown graphically and were examined for several values of the dimensionless parameters. It is observed that for different ferromagnetic interaction parameters and variable viscosity parameters, the velocity distribution decreases while temperature distribution increases. The magnitude of skin friction coefficient and the rate of heat transfer decrease with the increasing values of radiation parameter and Prandtl number. The results are also compared for specific values of the parameters with others documented in the literature.
\end{abstract}

(C) 2020 The Author(s). Published by TAF Publishing.

\section{INTRODUCTION}

A biomagnetic fluid is a fluid that exists in a living creature and its flow is influenced by the presence of a magnetic field. The most common example of biomagnetic fluid is blood. Blood is also a magnetic fluid due to its complex interaction of protein, cell membrane, and hemoglobin from iron oxides. During the last decades extensive work has been done on the dynamics of biological fluids in the presence of magnetic field. Numerous applications have been proposed in bio-engineering and medical sciences, such as: magnetic devices development for cell separation, reducing bleeding during surgeries, drug delivery using magnetic particles for the treatment of cancer tumors, hyperthermia.

Biomagnetic Fluid Dynamics(BFD) [1, 2, 3, 4, 5] is a relatively new area based on FHD and MHD investigating the fluid dynamics of biological fluids in the presence of mag- netic fields. The BFD model was first developed by Haik et al. [1]. This model is based on the principle of FHD. Andersson and Valnes [6] extended Cranes problem by studying the influence of the magnetic field due to a magnetic dipole, on a shear driven motion of a viscous nonconducting ferrofluid. The fluid flow formulated as a five parameter problem, and the influence of the magneto-thermo-mechanical coupling explored numerically. It was concluded that the primary Effect of the magnetic field was to decelerate the fluid motion as compared to the hydrodynamic case. In their study, they also considered that magneto-thermomechanical coupling is completely described by assuming that the applied magnetic field is sufficiently strong to saturate the ferrofluid and the variation of magnetization $\mathrm{M}$ with temperature $\mathrm{T}$ can be approximated by the linear equation of state $\mathrm{M}=\mathrm{K}\left(T_{c}-\mathrm{T}\right)$ Where Cranes [7] problem is

\footnotetext{
${ }^{*}$ Corresponding author: Md. Ghulam Murtaza

†email: limonn@yahoo.com
} 
one of the flow problem in the boundary layer theory that possesses an exact solution. In Cranes problem the stretching velocity is linearly proportional to distance from the origin. Misra et al. [8] investigated the biomagnetic fluid flow and heat transfer over a stretching sheet and considered the fluid's viscoelastic property.

In recent years, Murtaza et al. [9] investigated the Effect of electrical conductivity and magnetization on the biomagnetic fluid flow over a stretching sheet. This model is based on the both principles of MHD and FHD. They found that the effect on the flow due to FHD is equally significant with that of MHD and consequently for this physical problem neither, the electrical conductivity and magnetization of blood can be considered negligible. Ferdows et al. [10] analyzed the Numerical study of blood flow and heat transfer through stretching cylinder in the presence of a magnetic dipole. In their study they found that for extension of BFD model blood flow is reduced and temperature enhanced rather than the formulation of MHD or FHD. Ferdows et al. [11] also investigated the study of dual solution in biomagnetic fluid flow and heat transfer over a nonlinear stretching/shrinking sheet, by using Lie group transformation method under the influence of a magnetic field generated owing to the presence of a magnetic dipole. They found that dual solution exists only in the case of a shrinking sheet. Murtaza et al. [12] investigated the Similarity solution of nonlinear stretched biomagnetic flow and heat transfer with singum function and temperature power law geometries. They concluded that skin friction coefficient and rate of heat transfer linearly decreases when the nonlinear stretching parameter increases.

Furthermore, mathematical model have been developed for blood flow and many authors like $[13,14]$ assumed blood as a Newtonian fluid. Eldesoky [13] studied the MHD blood flow of an unsteady parallel plate in the presence of heat source. Misra and Sinha [15] studied the MHD flow of blood in a capillary with lumen being porous and wall permeable. Voltairas et al. [16] and Ruuge et al. [17] investigated the behavior of a blood flow when exposed to magnetic field has its applications in the development of magnetic devices for cell separation, targeted transport of drugs using magnetic particles as drug carries.

It is known that the physical properties of the fluid may change significantly with the temperature, especially for fluid viscosity. The temperature leads to the increase in the transport phenomena by reducing the viscosity across the momentum boundary layer and due to which the heat transfer rate at the wall is also affected. Therefore, to predict the flow and heat transfer rates it is necessary to take into account the temperature viscosity of the fluid. Salem [18] investigated variable viscosity and thermal conductivity effects on MHD flow and heat transfer in viscoelastic fluid over a stretching sheet. Malik et al. [19] demonstrated the variable viscosity of Eyring-Powell fluid over a stretching cylinder. They used two models Reynold's and Vogel's to deliberate the variable viscosity of the fluid. Singh et al. [20] studied the variable viscosity of Maxwell fluid with variable thermal conductivity over an exponential stretching sheet. They analyzed that the velocity of the fluid decreases with increase in variable viscosity parameter as related to constant fluid viscosity parameter. Alinejad et al. [21] discussed the two dimensional flow of a viscous fluid over a non-linear stretching sheet. They found that for small prandtl number the velocity boundary layer is minimum than the thermal boundary layer whereas for large prandtl number the temperature increases negative value after reaching zero.

\section{A. Purpose of Research}

The main purpose of the present study is the biomagnetic fluid flow and heat transfer over a nonlinear stretching sheet within the influence of an applied magnetic field generated by a magnetic dipole. The fluid viscosity is assumed to vary linearly with the temperature. It is hoped that the present study provides some insight of a basic biomagnetic fluid flow configuration for a particularly predicted range of the parameters and this analysis will be used in bio-medical and bio-engineering sciences.

\section{MODEL ANALYSIS}

A steady two dimensional flow of an laminar, incompressible, viscous and electrically non conducting fluids past a nonlinear stretching sheet. The flow is caused by the action of two equal and opposite forces along the horizontal direction which is taken as the $x$-axis, and the direction normal to the flow as the $Y$-axis. The sheet is stretched is a velocity $u=c x$, which is proportional to the distance of the origin. A magnetic dipole generated a magnetic field of strength which is located below the sheet at a distance $d$. The temperature of the sheet $T_{w}$ is kept fixed and $T_{\infty}$ is far away from the sheet, whereas $T_{w}<T_{\infty}$. 


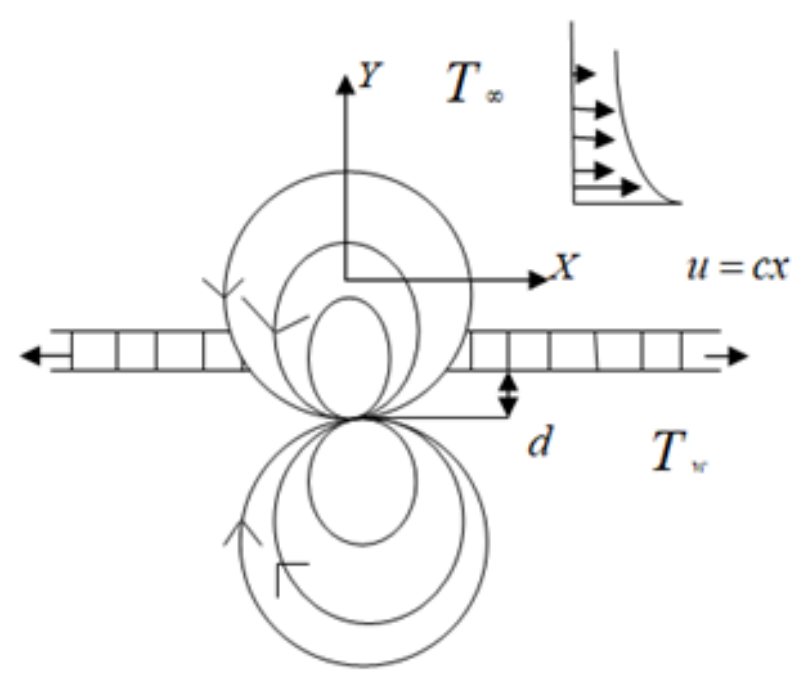

Fig. 1. Physical model and co-ordinate system of the problem

The equations governing the problem are given by:

$$
\begin{aligned}
& \frac{\partial u}{\partial x}+\frac{\partial v}{\partial y}=0 \\
&(1) \quad u \frac{\partial u}{\partial x}+v \frac{\partial u}{\partial y}=\frac{1}{\rho} \frac{\partial}{\partial y}\left(\mu \frac{\partial u}{\partial y}\right)+\frac{\mu_{0}}{\rho} \mathrm{M} \frac{\partial \mathrm{H}}{\partial x} \\
& \rho c_{p}\left(u \frac{\partial \mathrm{T}}{\partial x}+v \frac{\partial \mathrm{T}}{\partial y}\right)+\mu_{0} \mathrm{~T} \frac{\partial \mathrm{M}}{\partial \mathrm{T}}\left(u \frac{\partial \mathrm{H}}{\partial x}+v \frac{\partial \mathrm{H}}{\partial y}\right)=\kappa \frac{\partial^{2} \mathrm{~T}}{\partial y^{2}}-\frac{\partial q_{r}}{\partial y}
\end{aligned}
$$

With appropriate boundary conditions:

$$
\left.\begin{array}{l}
u=c x, v=0, \mathrm{~T}=T_{v} \text { at } y=0 \\
u \rightarrow 0, \mathrm{~T} \rightarrow T_{\infty} \text { as } y \rightarrow \infty
\end{array}\right\}
$$

Where $u$ and $v$ are the velocity components along $X$ and $Y$ directions respectively, $\rho$ is the fluid density, $\mu$ the dynamic viscosity, $\vartheta=\frac{\mu}{\rho}$ the kinematic viscosity, $\kappa$ thermal conductivity of fluid. $T$ and $T_{\infty}$ are fluid temperature within the boundary layer and fluid temperature in the free stream $\cdot c_{p}$ is the specific at constant pressure, $q$, is the radiative heat flux, $M$ the magnetization, $H$ the magnetic field of the fluid, $\mu_{0}$ the magnetic permeability, $T_{w}$ is the temperature of the surface, $c$ is a constant.

The term $\mu_{0} \mathrm{M} \frac{\partial \mathrm{H}}{\partial x}$ in Equation (2) denote the component of magnetic force per unit volume and depend on the presence of magnetic gradient. When the magnetic gradient is absent this force will vanish. The second term, on the left hand side of the thermal energy Equation (3) accounts for heating due to adiabatic magnetization. We consider that the components $H_{x}$ and $H_{y}$ of the magnetic field $H=\left(H_{x}, H_{y}\right)$, due to a magnetic dipole, are given by [22].

$$
\begin{aligned}
& H_{x}(x, y)=-\frac{\partial V}{\partial x}=\frac{\gamma}{2 \pi} \frac{x^{2}-(y+d)^{2}}{\left[x^{2}-(y+d)^{2}\right]^{2}} \\
& H_{y}(x, y)=-\frac{\partial V}{\partial y}=\frac{\gamma}{2 \pi} \frac{2 x(y+d)}{\left[x^{2}+(y+d)^{2}\right]^{2}}
\end{aligned}
$$

Where,

$$
V=\frac{\alpha}{2 \pi} \frac{x}{x^{2}+(y+d)^{2}}
$$

is a scalar potential of the magnetic dipole, $\gamma=\alpha$ and $\alpha$ is a dimensionless distance defined as

$$
\alpha=\sqrt{\frac{c}{\vartheta \infty}} d
$$

Thus the magnetic $\|\overrightarrow{\mathrm{H}}\|=\mathrm{H}$

of the magnetic field intensity, is given by

$$
\mathrm{H}(x, y)=\left[\mathrm{H}_{x}^{2}+\mathrm{H}_{y}^{2}\right]^{\frac{1}{2}}=\frac{\gamma}{2 \pi}\left[\frac{1}{(y+d)^{2}}-\frac{x^{2}}{(y+d)^{4}}\right]
$$

and the gradients given by,

$$
\begin{gathered}
\frac{\partial H}{\partial x}=\frac{\gamma}{2 \pi} \frac{-2 x}{(y+d)^{4}} \\
\frac{\partial H}{\partial y}=\frac{\gamma}{2 \pi}\left[\frac{-2}{(y+d)^{3}}+\frac{4 x^{2}}{(y+d)^{5}}\right]
\end{gathered}
$$

When the applied magnetic field $H$ is sufficiently strong to saturate the biomagnetic fluid, the magnetization $M$ is generally, determined by the fluid temperature. Anderson and Valnes [6] considered that the variation of magnetization $\mathrm{M}$ with temperature $\mathrm{T}$ can be approximated, by the linear equation, $\mathrm{M}=\mathrm{K}\left(\mathrm{T}-T_{\infty}\right)$, where $\mathrm{K}$ is a constant. Lai and Kulacki [23] has assumed the fluid viscosity is an inverse linear function of temperature.

$$
\frac{1}{\mu}=\frac{1}{\mu_{\infty}}\left[1+\gamma\left(\mathrm{T}-T_{\infty}\right)\right]
$$




$$
\text { Or, } \frac{1}{\mu}=a\left(\mathrm{~T}-T_{r}\right)
$$

Here

$$
a=\frac{\gamma}{\mu_{\infty}}, T_{r}=T_{m}-\frac{1}{\gamma}, \mu_{\infty}=\rho \vartheta_{\infty}
$$

$\gamma$ is constant, $\mu_{\infty}$ is the dynamic viscosity at infinity, $\vartheta_{\infty}$ is the kinematic viscosity at infinity, $T_{r}$ is the reference temperature, $T_{\infty}$ is the temperature at infinity, $a$ is constant which in general is positive for liquids and negative for gases.

In the case of an optically thin gray fluid the local radiant absorption is expressed as [24, 25, 26],

$$
-\frac{\partial q_{r}}{\partial x}=4 a^{*} \sigma^{*}\left(T_{\infty}^{4}-T^{4}\right)
$$

Where, $a$ " is the absorption coefficient and $\sigma$ is the StefanBoltzman constant. We assume that the temperature differences within the flow are sufficiently small such that $T^{4}$ may be expressed as a linear function of the temperature. This is accomplished by expanding in a Taylor series about and $T_{\text {neglecting higher-order terms, thus. }}$

$$
T^{4} \cong 4 T_{\infty}^{3} \mathrm{~T}-3 T_{\infty}^{4}
$$

Equation (8) through (9) takes the form:

$$
-\frac{\partial q_{r}}{\partial x}=16 a^{*} \sigma^{*} T_{\infty}^{3}\left(T_{\infty}-\mathrm{T}\right)
$$

In mathematic analysis, the following non dimensional variables are introduced,

$$
u=c x f^{\prime}(\eta), v=-\sqrt{c \nu_{\infty}} f(\eta), \eta(y)=\sqrt{\frac{c}{v_{m}}} y, \theta(\eta)=\frac{\mathrm{T}-T_{\infty}}{T_{w}-T_{\omega}}
$$

Where, $\eta$ is the dimensionless similarity variable and Prime denotes the differentiation with respect to $\eta$.

Using the similarity variable and dimensionless tempera- ture, the governing equations reduced to the following ordinary differential equations:

$$
f^{\prime \prime}-\frac{\theta}{\theta-\theta_{r}} f^{\prime \prime}-\frac{\theta-\theta_{r}}{\theta_{r}} f f^{\prime}+\frac{\theta-\theta_{r}}{\theta_{r}} f^{\prime 2}+\frac{\theta-\theta_{r}}{\theta_{r}} \frac{2 \beta \theta}{(\eta+\alpha)^{4}}=0
$$

$$
\theta^{\prime \prime}+\operatorname{Prf} \theta^{\prime}-2 \beta \lambda(\varepsilon+\theta) \frac{1}{(\eta+\alpha)^{3}} f-S \theta=0
$$

The transformed dimensionless boundary conditions are:

$$
\begin{aligned}
& \left.\begin{array}{c}
f^{\prime}=1, f=0, \theta=1, \text { at } \eta=0 \\
f^{\prime} \rightarrow 0, \theta \rightarrow 0, \text { as } \eta \rightarrow \infty
\end{array}\right\} \\
& \qquad \begin{array}{l}
\mathrm{P} r=\frac{\mu_{\infty} C_{p}}{\kappa}, \lambda=\frac{c \mu^{2}}{\rho \kappa\left(\mathrm{T}_{w}-\mathrm{T}_{\infty}\right)} \\
\theta_{r}=\frac{\mathrm{T}_{r}-\mathrm{T}_{\infty}}{\mathrm{T}_{w}-\mathrm{T}_{\infty}}, \alpha=\sqrt{\frac{c}{\vartheta_{\infty}}} d
\end{array} \\
& \text { the shear stress } \tau_{w} \text { at the sheet is g } \\
& C_{f}=\frac{\tau_{y}}{\rho_{\infty} U_{v}^{2}}=-\frac{\theta_{r}}{\theta-\theta_{r}} R_{e} \frac{-1}{2} f^{\prime}(0) \\
& \text { where, } \tau_{v}=\mu\left(\frac{\partial u}{\partial y}\right)_{y-0}
\end{aligned}
$$$$
\mathrm{P} r=\frac{\mu_{\infty} C_{p}}{\kappa}, \lambda=\frac{c \mu^{2}}{\rho \kappa\left(\mathrm{T}_{w}-\mathrm{T}_{\infty}\right)}, \varepsilon=\frac{\mathrm{T}_{\infty}}{\mathrm{T}_{w}-\mathrm{T}_{\infty}}, \beta=\frac{\gamma}{2 \pi} \frac{\mu_{\circ} \mathrm{K}\left(\mathrm{T}_{w}-\mathrm{T}_{\infty}\right) \rho}{\mu_{\infty}^{2}}, S=\frac{16 a^{*} \sigma^{*} \mathrm{~T}^{3}, \vartheta_{\infty}}{k c}
$$

The seven parameters, which appears explicitly in the transformed problem, are the prandtl number $\mathrm{P} r$, viscous dissipation parameter $\lambda$, the dimensionless Curie temperature $\varepsilon$, the ferromagnetic interaction parameter $\beta$, radiation parameter $S$, viscosity variation parameter $\theta_{r}$ and the dimensionless distance $\alpha$ from the origin to the centre of the magnetic pole, defined respectively as:
The local skin friction co-efficient $C_{f}$, which is a dimensionless form of the shear stress $\tau_{w}$ at the sheet is given by,

The local heat flux as the local Nusselt number as follows:

$$
\begin{aligned}
& N_{u}=\frac{x q_{v}}{k\left(\mathrm{I}_{w}-\mathrm{T}_{\infty}\right)}=-R_{e} \frac{1}{2} \theta \\
& \text { where, } q_{v}=-k\left(\frac{\partial \mathrm{T}}{\partial y}\right)_{y-0}
\end{aligned}
$$

\section{RESULTS AND DISCUSSION}

The system of Equations (12) and (13) subject to the boundary conditions (14) has been solved by using bvp4c function technique in MATLAB software.

The effect of different physical parameters such as prandtl number, ferromagnetic interaction parameter, radiation parameter, viscosity variation parameter on velocity and temperature distributions, as well as skin friction co-efficient and the rate of heat transfer co-efficient are illustrated through the graph.

The accuracy of the numerical scheme is justified with those tabulated by Ioan Pop [27] for the values of $\mathrm{P} r=10$ while viscosity parameter $\theta$, ranging from -10 to 10 and the results are in very good agreement. 
TABLE 1

\begin{tabular}{|c|c|c|c|c|}
\hline \multirow[t]{2}{*}{$\theta_{r}$} & \multicolumn{2}{|c|}{ Present Results } & \multicolumn{2}{|c|}{ Ioan Pop [27] } \\
\hline & $-f^{\prime \prime}(0)$ & $-\theta^{\prime}(0)$ & $f^{\prime \prime}(0)$ & $\theta^{\prime}(0)$ \\
\hline-10 & -.506411 & -1.671852 & -.5067231 & -1.6815592 \\
\hline-8 & -.515606 & -1.670456 & -.5157982 & -1.6731001 \\
\hline-6 & -.530751 & -1.668148 & -.5310019 & -1.6706682 \\
\hline-4 & -.560385 & -1.663601 & -.5607505 & -1.6658760 \\
\hline-2 & -.644386 & -1.650402 & -.6450530 & -1.6520581 \\
\hline-1 & -.793261 & -1.626345 & -.7955242 & -1.6330620 \\
\hline 2 & -.258093 & -1.708198 & -.2570983 & -1.7128251 \\
\hline 4 & -.368489 & -1.692353 & -.3680423 & -1.696152 \\
\hline 6 & -.402973 & -1.687303 & -.4026855 & -1.6908461 \\
\hline 8 & -.419812 & -1.684819 & -.4196006 & -1.6882310 \\
\hline 10 & -.429791 & -1.683341 & -.4296234 & -1.6866740 \\
\hline
\end{tabular}

The values of governing parameters are chosen to be physically representative of the actual blood fluids. In figures 2 to 30 , the following data are utilize:

1. Ferromagnetic interaction parameter $\beta=0,1,5,10$ as in $[8,28,29,30]$. Noted that $\beta=0$ corresponds to hydrodynamic flow.

2. Values of dimensionless distance $\alpha=1$ as in [28].

3 . Viscosity variation parameter.

$\theta_{r}=-.6,-.4,-.2$ as in [31].

4. Prandt number $\mathrm{P} r=21,23,25$ as in [11].

5. Radiation parameter $S=1,2,3$ as in [6].

As the fluid is blood, we consider a human body temperature $T_{n}=37^{\circ} \mathrm{c}$, where as the body curie temperature is $T_{\infty}=41^{0} c$ according to Loukopoulos and Tzizrtzilakis [32]. For these values of temperature, the dimensionless temperature is $\varepsilon=78.5$ and viscous dissipation parameter $\lambda=6.4 \times 10^{-14}$. Also we assume that $\rho=$ $1050 \mathrm{kgm}^{-3}, \mu=3.2 \times 10^{-3} \mathrm{~kg} \mathrm{~m}^{-3} \mathrm{~s}^{-3}$, according to $\mathrm{Tz}$ izrtzilakis [22] The specific heat under a constant pressure $c_{p}$ and thermal conductivity $\kappa$ of any fluid are temperature dependent. For the temperature range, consider this prob- lem $C_{p}=14.65 j \mathrm{~kg}^{-1} k^{-1}, \kappa=2.2 \times 10^{-3} j(\mathrm{msk})^{-1}$ according to Tzizrtzilakis and Xenos [33] and hence $\mathrm{Pr}=21$

Figure 2 and Figure 3 show that the effect of ferromagnetic parameter on velocity and temperature profiles. It can be observed that velocity of the fluid decreases with an increase of magnetic number, where as temperature distribution increases in this case. The main fact is that the ferromagnetic number is directly related to Kelvin force, which is also known as drug force.

Figure 4 and Figure 5 depict the effect of Prandtl number on velocity and temperature profiles. It can be seen from these figures that have more pronounced effect on the temperature profiles rather that on velocity. This is readily to be understood since is the ratio of momentum diffusivity to thermal diffusivity in the convection boundary layer region. Figure 6 and 7 indicate that with increase in the values $\theta_{r}$, the velocity decreases and enhances the temperature profile. This is because the increase $\theta_{r}$ results in an increase in the themal boundary layer thickness, which results in a decrease in the velocity and increase in the temperature.

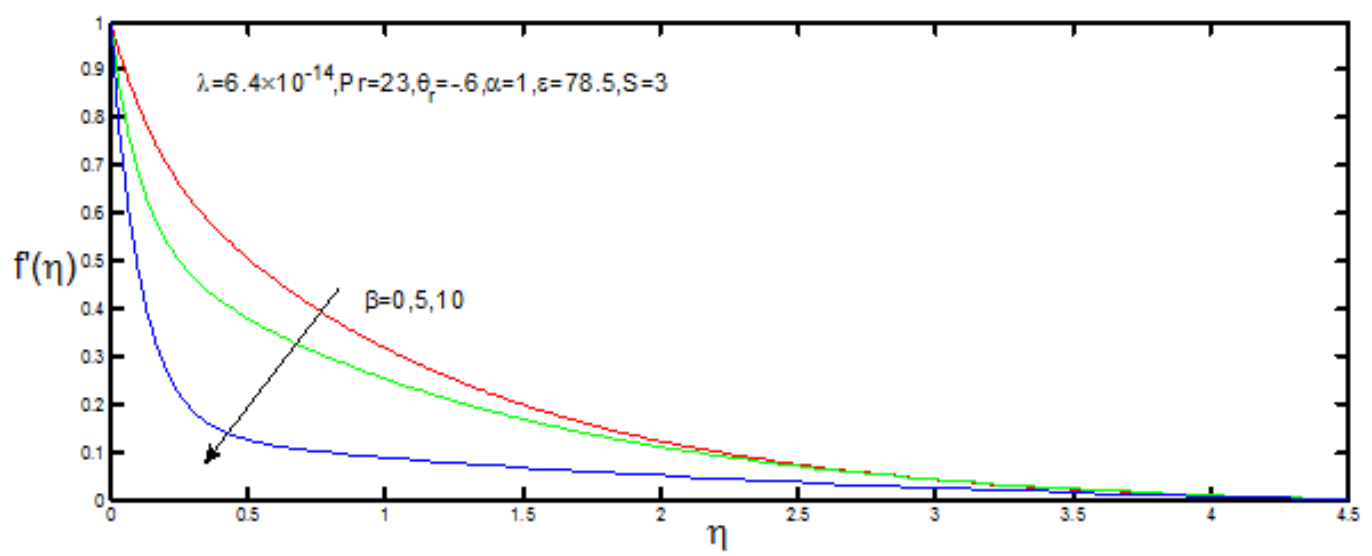

Fig. 2. Velocity Profile for $f^{\prime}(\eta)$ for various values of $\beta$ 


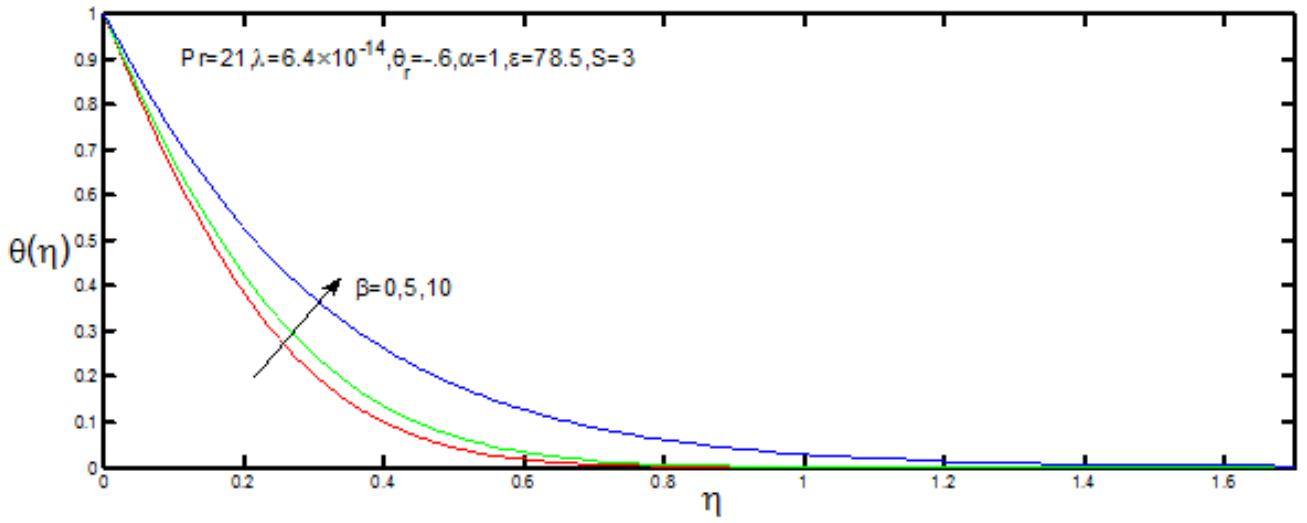

Fig. 3. Temperature Profile for $\theta(\eta)$ for vanious values of $\beta$

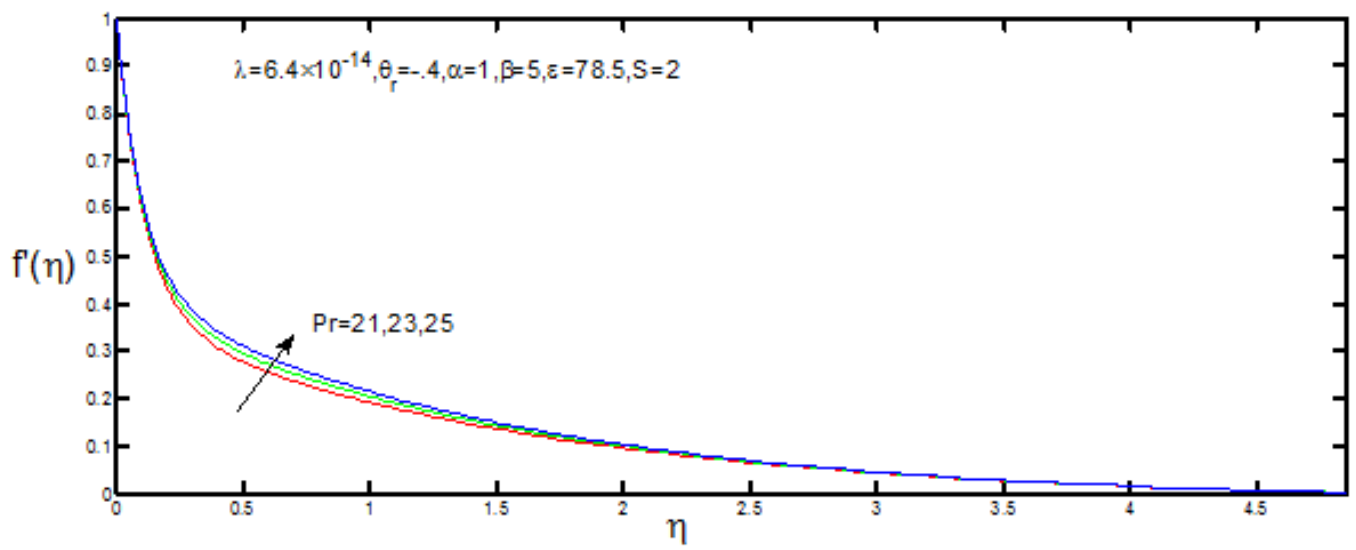

Fig. 4. Velocity profile for $f^{\prime}(\eta)$ for various values of $\operatorname{Pr}$

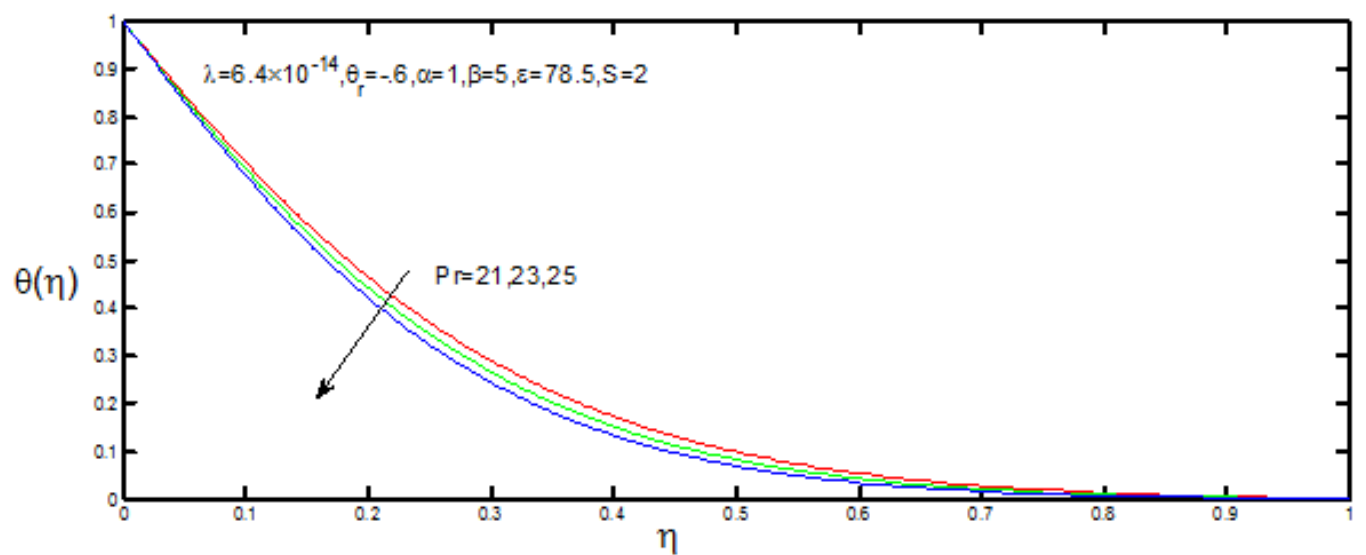

Fig. 5. Temperature profile for $\theta(\eta)$ for vanious values of $\operatorname{Pr}$ 


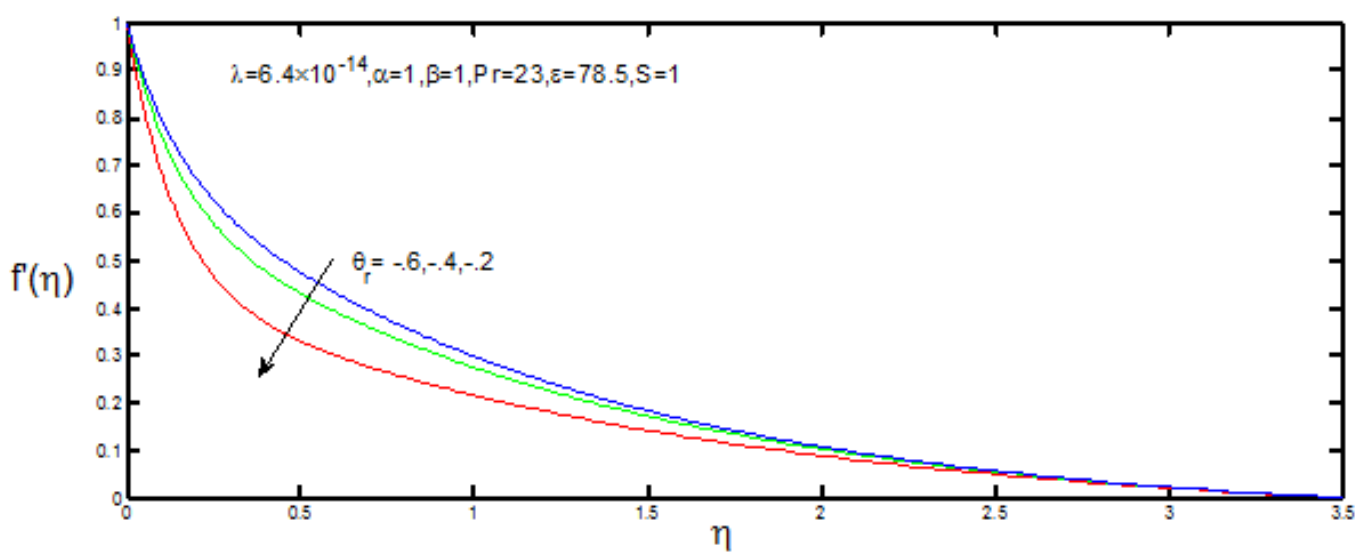

Fig. 6. Velocity profile for $f^{\prime}(\eta)$ for various values of $\theta_{r}$

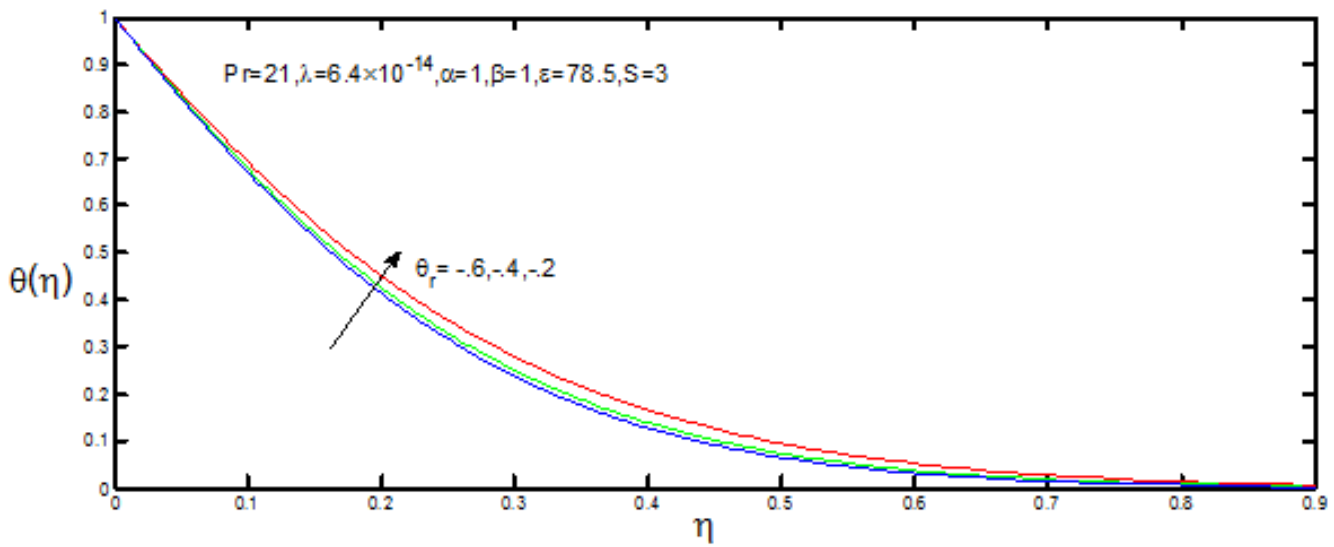

Fig. 7. Temperature profile for $\theta(\eta)$ for various values of $\theta_{r}$

Figure 8 and 9 shows that the effect of radiation parameter on velocity and temperature profiles. The presence and increase of thermal radiation parameter augment the temperature values in the thermal boundary layer. According to the definition of radiation parameter, increase of, implies decrement of absorption coefficient. So that, the rate of energy transport to the fluid and the values of temperature distribution increases.

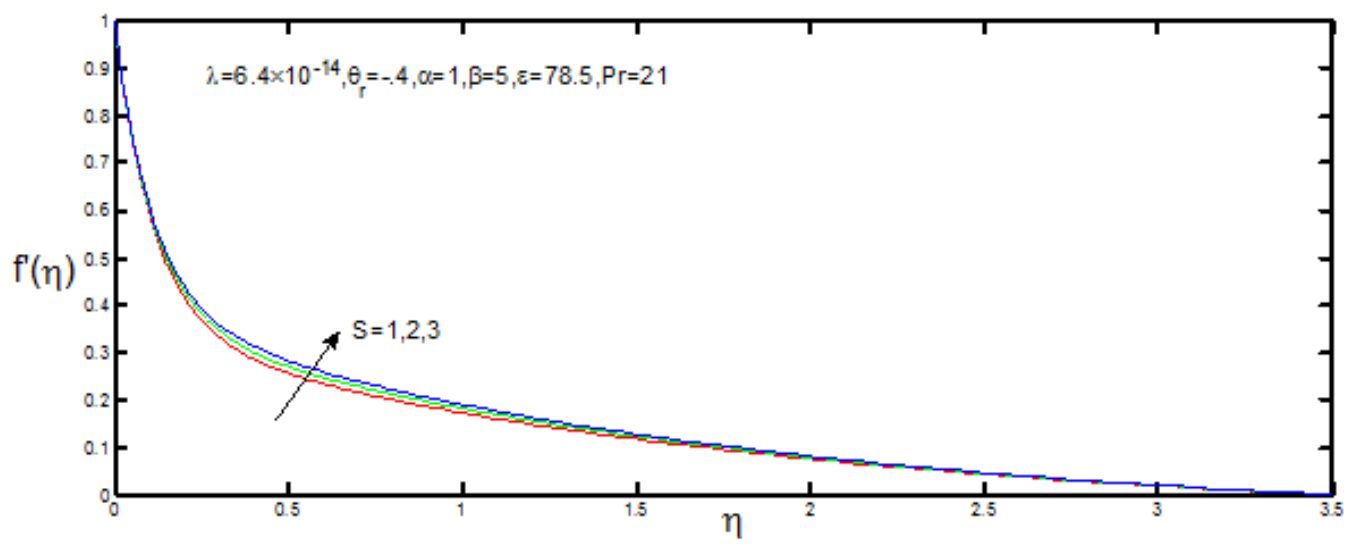

Fig. 8. Velocity profile for $f^{\prime}(\eta)$ for various values of $S$ 


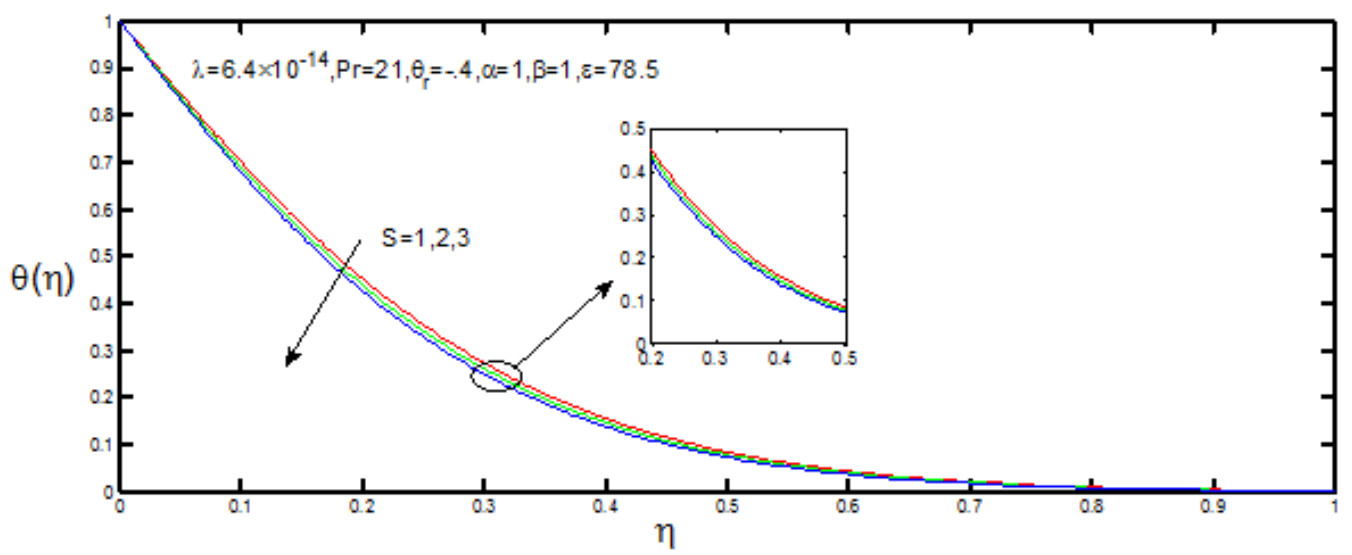

Fig. 9. Temperature profile for $\theta(\eta)$ for various values of $S$

Figures 10 to 31 demonstrate the variation of the skin friction coefficient $f^{\prime \prime}(0)$ and rate of heat transfer $\theta^{\prime}(0)$ with the ferromagnetic parameter, viscosity parameter, radiation parameter and Prandt number. Figures 10, 11 display the ef- fect of $\theta_{r}$ on $f^{\prime \prime}(0)$ and $\theta^{\prime}(0)$. According to the figures $f^{\prime \prime}(0)$ decreases with increasing values of $\theta$, whereas $\theta^{\prime}(0)$ increases.

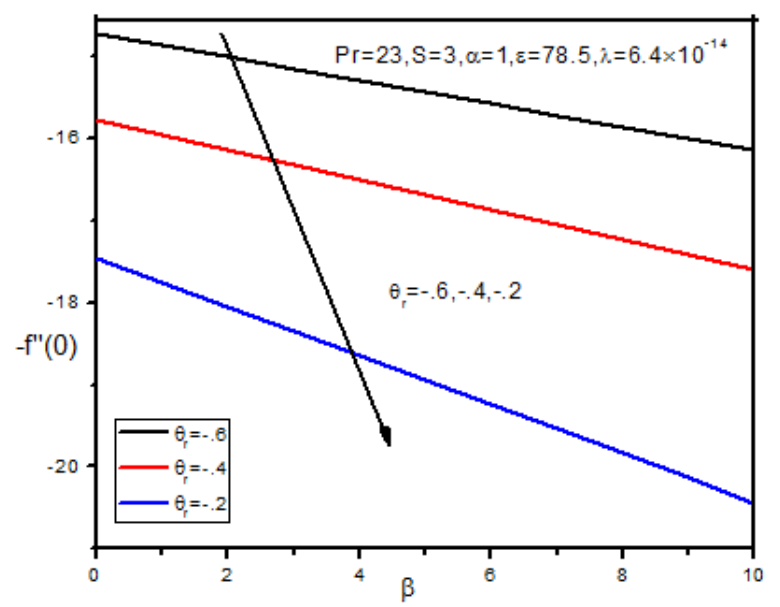

Fig. 10. Skin friction coefficient $-f^{\prime \prime}(0)$ with $\beta$ for different values of $\theta_{r}$

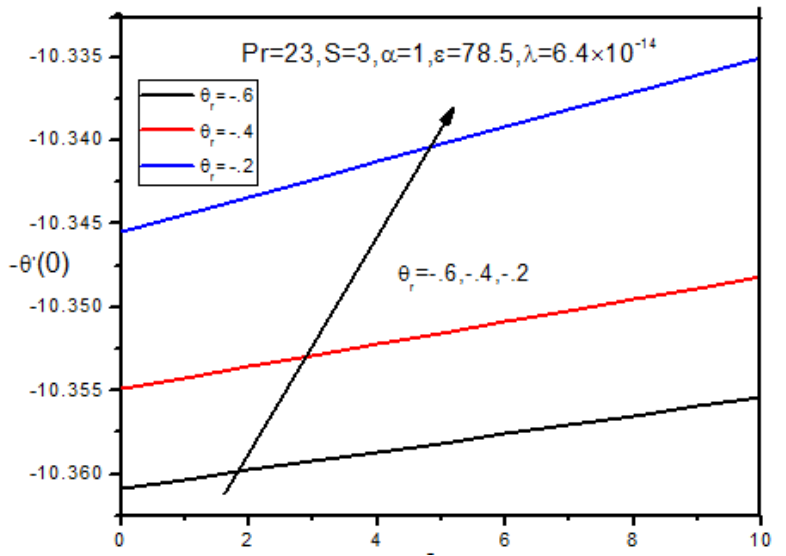

Fig. 11. Local nusselt number $-\theta^{\prime}(0)$ with $\beta$ for different values of $\theta_{r}$ 
Figures 12, 13 depict the rate of heat transfer $\theta^{\prime}(0)$ with respect to the $\beta$ for different values of the $\mathrm{P} r$ and $S$.It is observed that the rate of heat transfer $\theta^{\prime}(0)$ decreases in both cases.

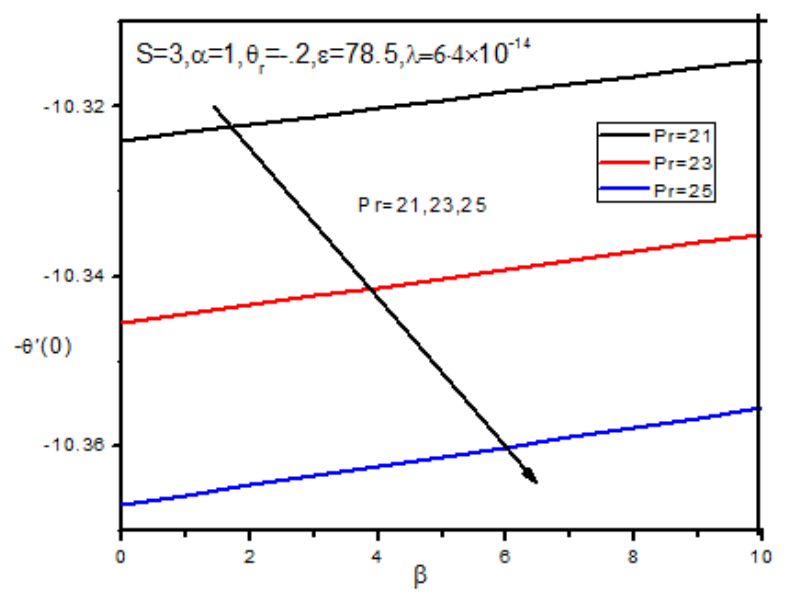

Fig. 12. Local nusselt number $-\theta^{\prime}(0)$ with $\beta$ for different values of P r

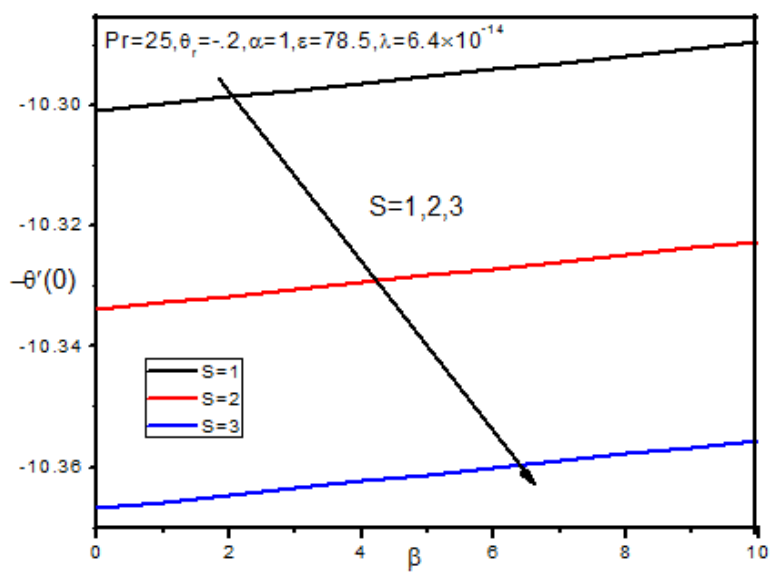

Fig. 13. Local nusselt number $-\theta^{\prime}(0)$ with $\beta$ for different values of $S$

Figures 14-19 display the effect of different values of $\beta, S, \theta$, on $f^{\prime \prime}(0)$ and $\theta^{\prime}(0)$ regard to Pr According to the figures $f^{\prime \prime}(0)$ decrease with increasing value of $\beta, \theta_{r}$ whereas $\theta^{\prime}(0)$ increases. It is noted the effect of $S$ on both $f^{\prime \prime}(0)$ and $\theta^{\prime}(0)$ are decrease with increasing value of $S$.

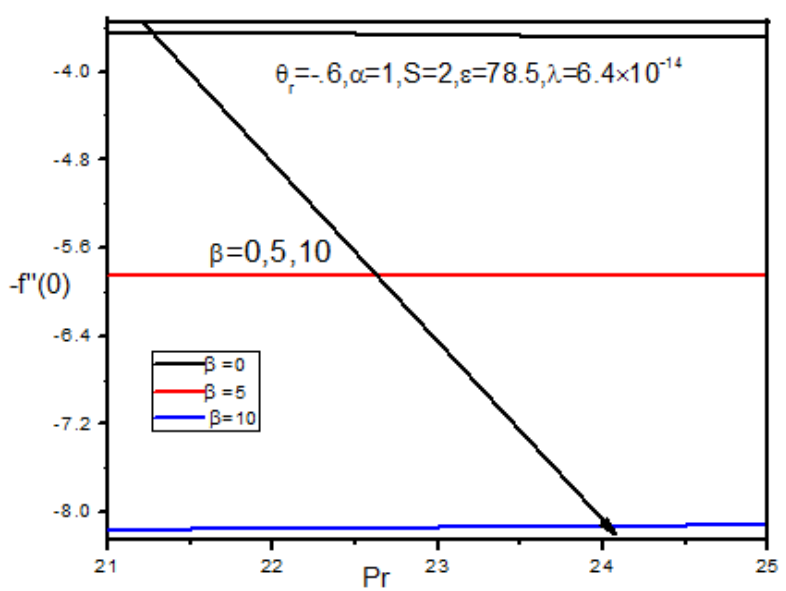

Fig. 14. Skin friction coefficient $-f^{\prime \prime}(0)$ with $\mathrm{P} r$ for different values of $\beta$

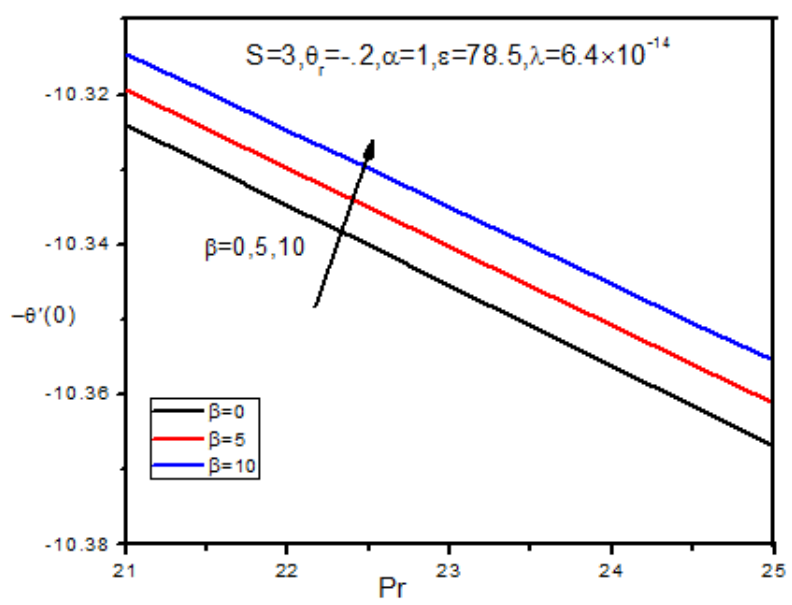

Fig. 15. Local nusselt number $-\theta^{\prime}(0)$ with $\mathrm{P} r$ for different values of $\beta$

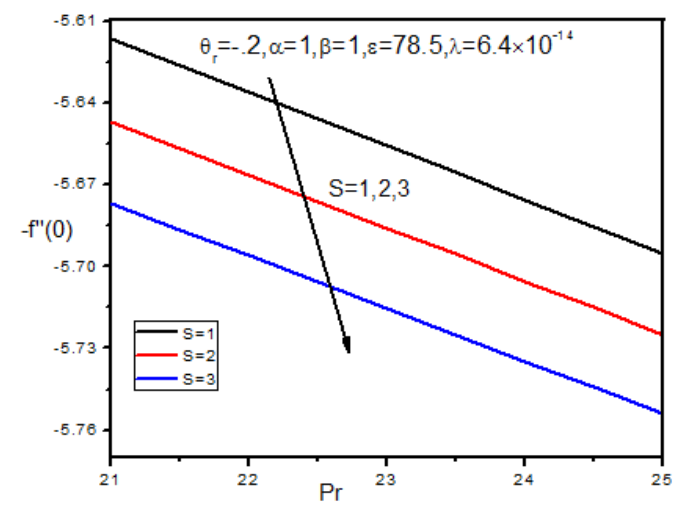

Fig. 16. Skin friction coefficient $-f^{\prime \prime}(0)$ with Pr for different values of $S$ 
Figures 20-24 display the effect of different values of $\beta, \operatorname{Pr}, \theta$, on $f^{\prime \prime}(0)$ and $\theta^{\prime}(0)$ regards to $S$. It is observed that $f^{\prime \prime}(0)$ decreases with the increment of $\beta, \theta_{r}$. whereas $\theta^{\prime}(0)$ increases. It is also noted that both $f^{\prime \prime}(0)$ and $\theta^{\prime}(0)$ decreases for the increment of Pr.

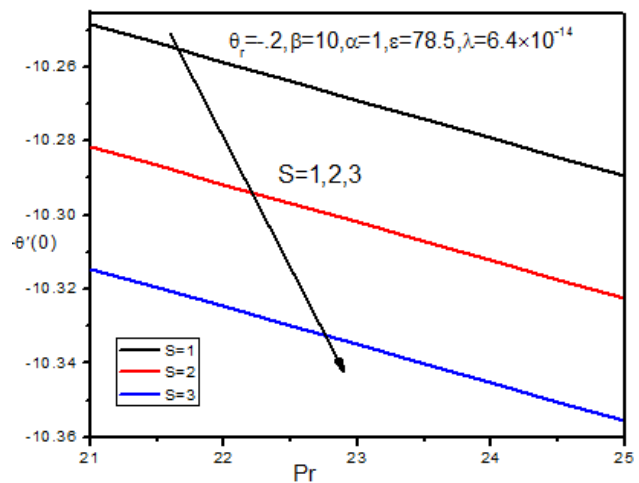

Fig. 17. Local nusselt number $-\theta^{\prime}(0)$ with Pr for different values of $S$

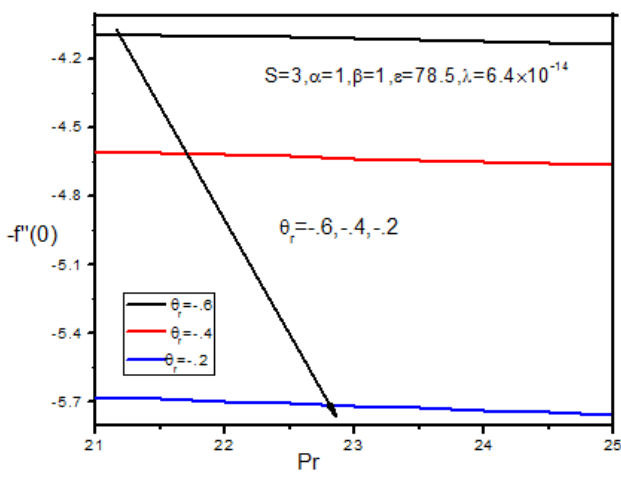

Fig. 18. Skin friction coefficient $-f^{\prime \prime}(0)$ with $\mathrm{P} r$ for different values of $\theta_{r}$

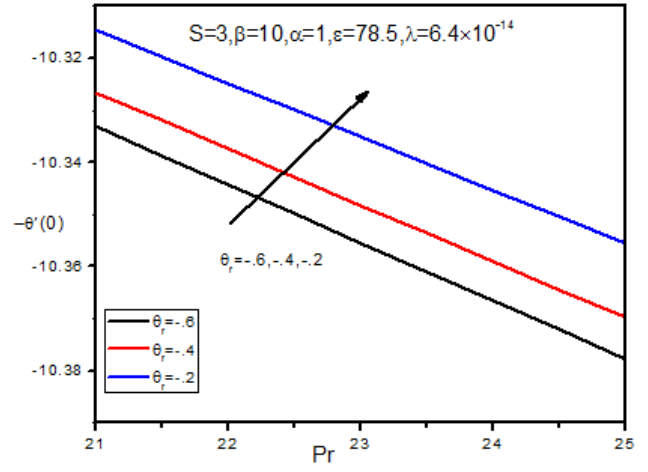

Fig. 19. Local nusselt number $-\theta^{\prime}(0)$ with $\mathrm{P} r$ for different values of $\theta_{r}$

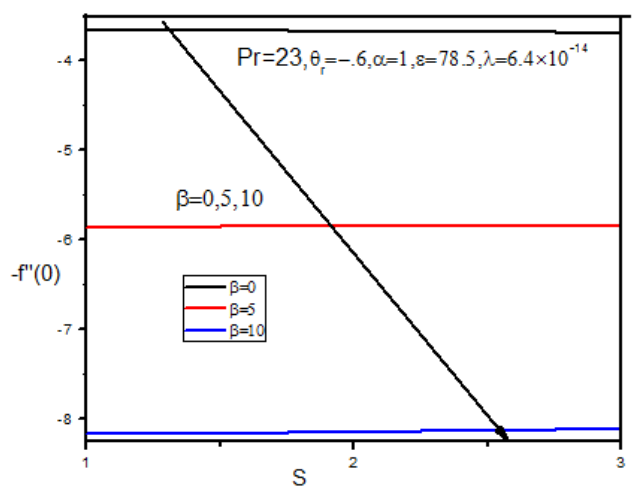

Fig. 20. Skin friction coefficient $-f^{\prime \prime}(0)$ with $S$ for different values of $\beta$

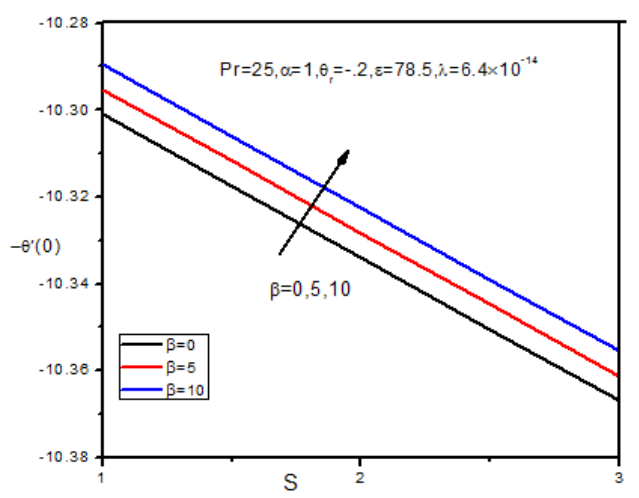

Fig. 21. Local nusselt number $-\theta^{\prime}(0)$ with $S$ for different values of $\beta$ 


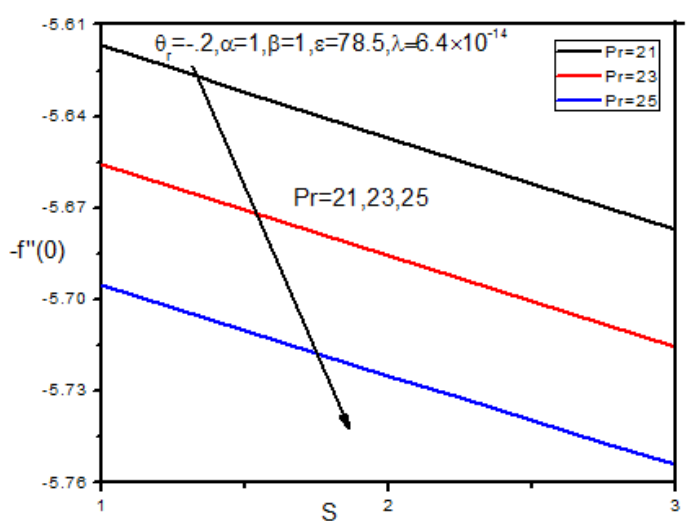

Fig. 22. Skin friction coefficient $-f^{\prime \prime}(0)$ with $S$ for different values of Pr

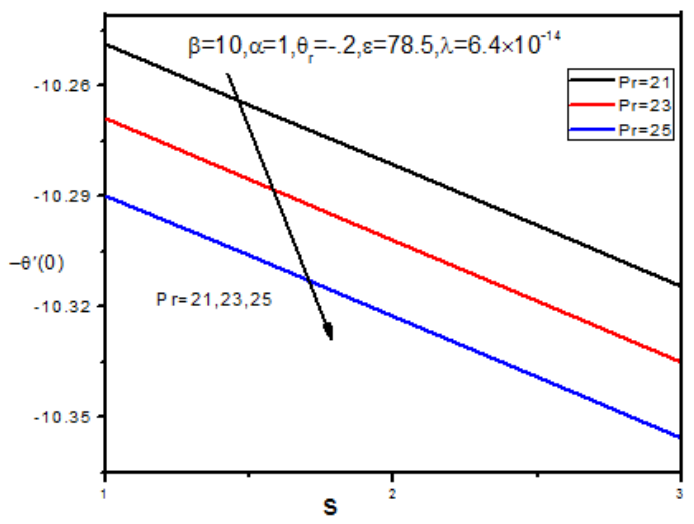

Fig. 23. Local nusselt number $-\theta^{\prime}(0)$ with $S$ for different values of $\mathrm{Pr}$

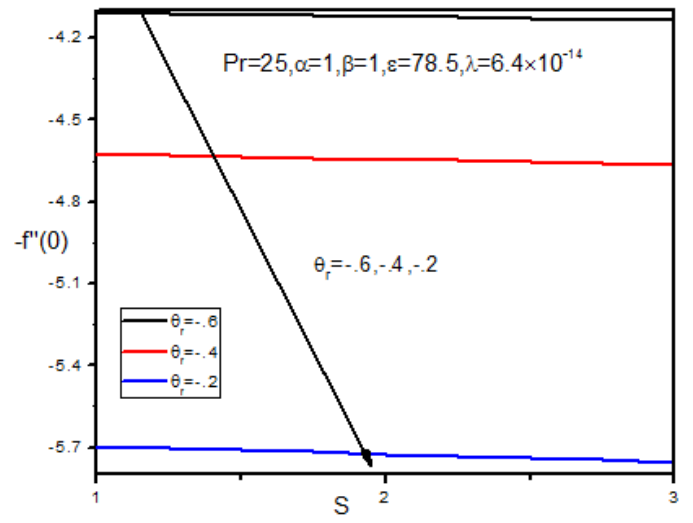

Fig. 24. Skin friction coefficient $-f^{\prime \prime}(0)$ with $S$ for different values of $\theta_{r}$

Figures 26-31 depict the $f^{\prime \prime}(0)$ and $\theta^{\prime}(0)$ with respect to $\theta$, for different values of $\mathrm{P}_{r}, \beta, S$ According to the figures $f^{\prime \prime}(0)$ decreases with increasing value of $\beta$ whereas $\theta^{\prime}(0)$ increases. It is clearly noted that both $f^{\prime \prime}(0)$ and $\theta^{\prime}(0)$ are decreases with increasing values of $\mathrm{P} r$ and $S$.

ISSN: $2414-4592$

DOI: $10.20474 /$ jater-6.1.2.

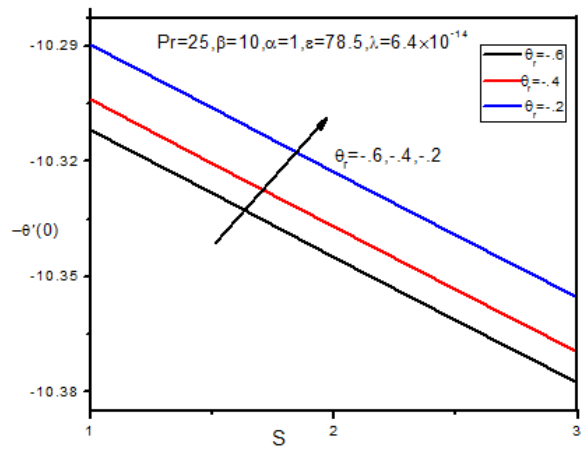

Fig. 25. Local nusselt number $-\theta^{\prime}(0)$ with $S$ for different values of $\theta_{r}$

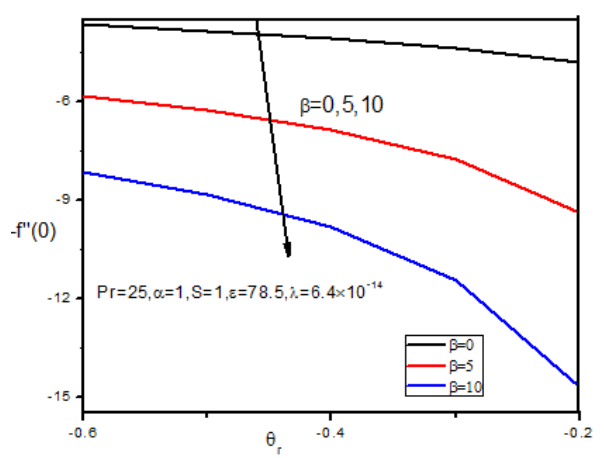

Fig. 26. Skin friction coefficient $-f^{\prime \prime}(0)$ with $\theta_{r}$ for different values of $\beta$

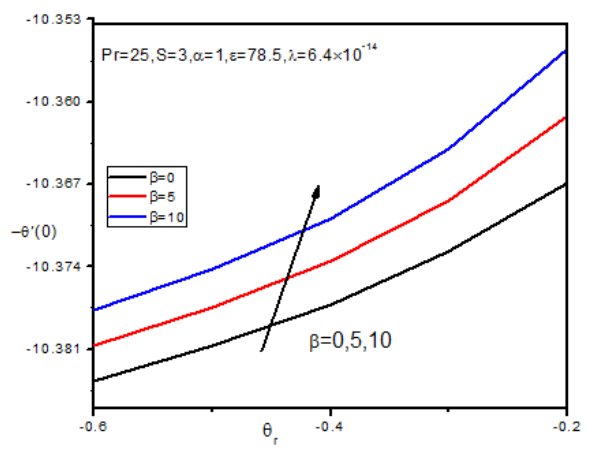

Fig. 27. Local nusselt number $-\theta^{\prime}(0)$ with $\theta_{r}$ for different values of $\beta$

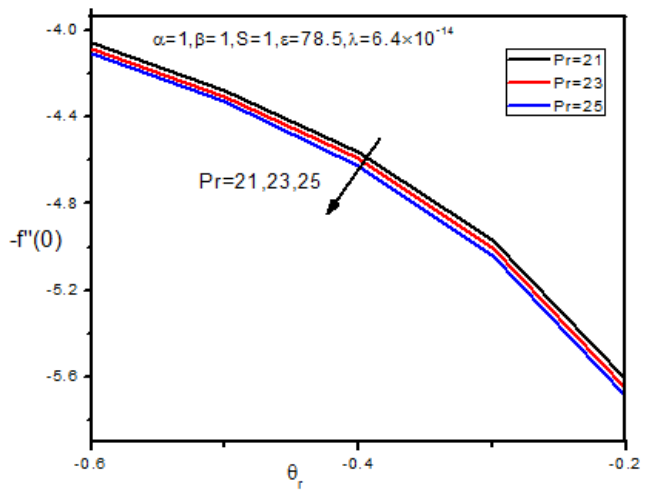

Fig. 28. Skin friction coefficient $-f^{\prime \prime}(0)$ with $\theta_{r}$ for different values of Pr 


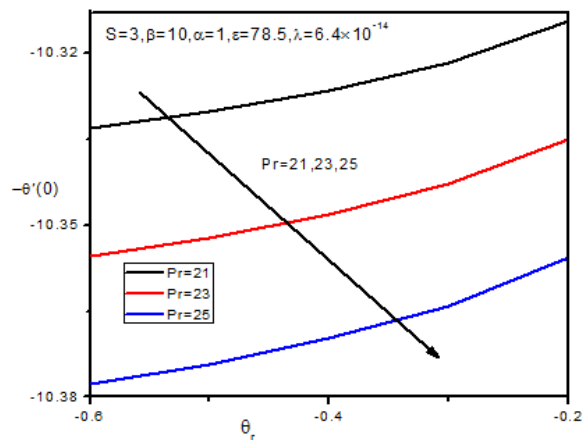

Fig. 29. Local nusselt number $-\theta^{\prime}(0)$ with $\theta_{r}$ for different values of $\mathrm{P} \mathrm{r}$

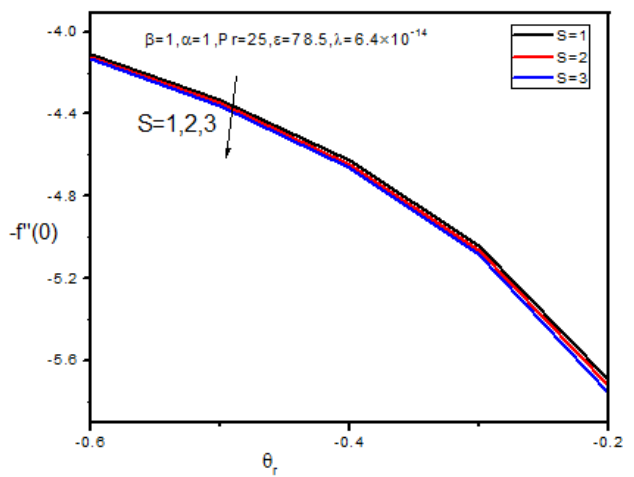

Fig. 30. Skin friction coefficient $-f^{\prime \prime}(0)$ with $\theta_{r}$ for different values of $S$

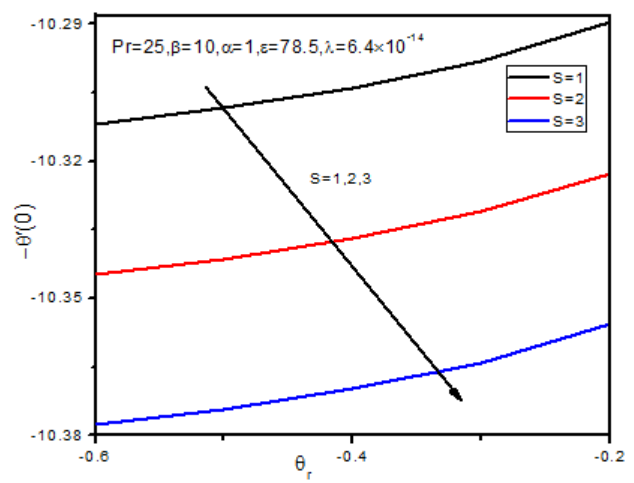

Fig. 31. Local nusselt number $-\theta^{\prime}(0)$ with $\theta_{r}$ for different values of $S$

\section{CONCLUSION}

This research investigated the characteristics of biomagnetic fluid specially for blood over a non linear stretching sheet and heat transfer from the sheet to the fluid: also the effects of the presence and intensity of ferromagnetic, radiation, variable viscosity and Prandtl number are considered. To obtain more exact solution, viscosity are supposed temperature dependent. From the present investigation the following conclusions were made:

- The velocity profile decreases with increasing values of ferromagnetic interaction parameter and variable viscosity parameter whereas temperature profile increases in all cases.

- The velocity profile increases with increasing values of Prandtl number and radiation parameter whereas temperature profile decreases in all cases.

- Skin friction coefficient decreases due to ferromagnetic interaction parameter and variable viscosity parameter whereas the rate of heat transfer increased in all cases.

- Both Skin friction coefficient and the rate of heat transfer decreases for radiation parameter and Prandtl number.

\section{LIMITATIONS AND FUTURE RESEARCH DIRECTIONS}

This study has some shortcomings for instance, this work has considered the biomagnetic fluid model and has been restricted to viscous and electrically nonconducting fluids and magnetic field in the absence of electrical conductivity of the fluids.

On the other hand, this study has enormous applications, to commence with, these investigations provide valuable information for biomedical sector to seek the understanding the flow of blood. Moreover, the outcomes of this study can be useful for many biomedical applications as such using magnetic nanoparticles in drug delivery and drug targeting. This study will extended with three dimensional blood flows pattern through channelflow in horizontal cylinder, cylindrical geometry with significant narrowing (mimickingstenosis) and cylindrical geometry with significant swelling (mimicking aneurysm) allowing magnetisation and Lorentz forces.

\section{REFERENCES}

[1] Y. Haik, J. Chen, and V. Pai, "Development of bio-magnetic fluid dynamics," in Proceedings of the IX International Symposium on Transport Properties in Thermal Fluids Engineering, Singapore, Pacific Center of Thermal Fluid Engineering, Hawaii, HI, 1996.

[2] Y. Haik, V. Pai, and C. Chen, "Biomagnetic fluid dynamics," Fluid Dynamics at Interfaces, vol. 6, no. 7, pp. 439-452, 1999.

[3] E. Tzirtzilakis, "A mathematical model for blood flow in magnetic field," Physics of Fluids, vol. 17, no. 7, pp. 77-86, 2005. doi: https://doi.org/10.1063/1.1978807 
[4] E. E, Tzirtzilakis, "Biomagnetic fluid flow in a channel with stenosis," Physica D: Nonlinear Phenomena, vol. 237, no. 1, pp. 66-81, 2008. doi: https://doi.org/10.1016/j.physd.2007.08.006

[5] S. Sarkar and V. Ilango, "Improvement of fuel cell performance by application of carbon nanotubes," International Journal of Technology and Engineering Studies, vol. 2, no. 6, pp. 180-184, 2016. doi: https://doi.org/10.20469/ijtes.2. 40003-6

[6] H. Andersson and O. Valnes, "Flow of a heated ferrofluid over a stretching sheet in the presence of a magnetic dipole," Acta Mechanica, vol. 128, no. 1-2, pp. 39-47, 1998. doi: https://doi.org/10.1007/bf01463158

[7] L. J. Crane, "Flow past a stretching plate," Zeitschrift Für aAngewandte Mathematik und Physik ZAMP, vol. 21, no. 4, pp. 645-647, 1970. doi: https://doi.org/10.1007/bf01587695

[8] J. Misra and G. Shit, "Flow of a biomagnetic visco-elastic fluid in a channel with stretching walls," Journal of Applied Mechanics, vol. 76, no. 6-14, 2009. doi: https://doi.org/10.1115/1.3130448

[9] M. Murtaza, E. Tzirtzilakis, and M. Ferdows, "Effect of electrical conductivity and magnetization on the biomagnetic fluid flow over a stretching sheet," Zeitschrift Für Angewandte Mathematik und Physik, vol. 68, no. 4, pp. 93-110, 2017. doi: https://doi.org/10.1007/s00033-017-0839-z

[10] M. Ferdows, M. Murtaza, E. Tzirtzilakis, and F. Alzahrani, "Numerical study of blood flow and heat transfer through stretching cylinder in the presence of a magnetic dipole," Journal of Applied Mathematics and Mechanics, vol. 5, no. 6, pp. 11-20, 2020. doi: https://doi.org/10.1002/zamm.201900278

[11] M. Ferdows, G. Murtaza, J. C. Misra, E. E. Tzirtzilakis, and A. Alsenafi, "Dual solutions in biomagnetic fluid flow and heat transfer over a nonlinear stretching/shrinking sheet: Application of lie group transformation method," Mathematical Biosciences and Engineering, vol. 17, no. 5, pp. 4852-4874, 2020. doi: https://doi.org/10.3233/jae-190101

[12] M. Murtaza, E. Tzirtzilakis, and M. Ferdows, "Similarity solutions of nonlinear stretched biomagnetic flow and heat transfer with signum function and temperature power law geometries," International Journal of Mathematical and Computational Sciences, vol. 12, no. 2, pp. 24-29, 2018. doi: https://doi.org/10.3390/sym12020253

[13] I. M. Eldesoky, "Mathematical analysis of unsteady mhd blood flow through parallel plate channel with heat source," in International Conference on Mathematics and Engineering Physics (ICMEP-6), Lonond, UK, 2012.

[14] A. N. Oumer, N. T. Rao, F. Basrawi, and H. Ibrahim, "Numerical simulation on flow and heat transfer characteristics of supercritical fluids in mini-channels," Journal of Advances in Technology and Engineering Research, vol. 2, no. 3, pp. 81-86, 2016. doi: https://doi.org/10.20474/jater-2.3.2

[15] J. Misra and A. Sinha, "Effect of thermal radiation on MHD flow of blood and heat transfer in a permeable capillary in stretching motion," Heat and Mass Transfer, vol. 49, no. 5, pp. 617-628, 2013. doi: https://doi.org/10.1007/ s00231-012-1107-6

[16] P. Voltairas, D. Fotiadis, and L. Michalis, "Hydrodynamics of magnetic drug targeting," Journal of Biomechanics, vol. 35, no. 6, pp. 813-821, 2002. doi: https://doi.org/10.1016/s0021-9290(02)00034-9

[17] E. Ruuge and A. Rusetski, "Magnetic fluids as drug carriers: Targeted transport of drugs by a magnetic field," Journal of Magnetism and Magnetic Materials, vol. 122, no. 1-3, pp. 335-339, 1993. doi: https://doi.org/10.1016/0304-8853(93) 91104-f

[18] A. M. Salem, "Variable viscosity and thermal conductivity effects on MHD flow and heat transfer in viscoelastic fluid over a stretching sheet," Physics Letters A, vol. 369, no. 4, pp. 315-322, 2007. doi: https://doi.org/10.1016/j.physleta. 2007.04.104

[19] M. Malik, A. Hussain, and S. Nadeem, "Boundary layer flow of an eyring powell model fluid due to a stretching cylinder with variable viscosity," Scientia Iranica, vol. 20, no. 2, pp. 313-321, 2013. doi: https://doi.org/10.1016/j.aej.2016.07. 037

[20] V. Singh and S. Agarwal, "Flow and heat transfer of maxwell fluid with variable viscosity and thermal conductivity over an exponentially stretching sheet," American Journal of Fluid Dynamics, vol. 3, no. 4, pp. 87-95, 2013. doi: https: //doi.org/10.1002/htj.21074

[21] J. Alinejad and S. Samarbakhsh, "Viscous flow over nonlinearly stretching sheet with effects of viscous dissipation," Journal of Applied Mathematics, vol. 2, no. 6, pp. 45-70, 2012. doi: https://doi.org/10.1155/2012/587834

[22] E. Tzirtzilakis, "A simple numerical methodology for BFD problems using stream function vorticity formulation," Communications in Numerical Methods in Engineering, vol. 24, no. 8, pp.683-700, 2008. doi: https://doi.org/10.1002/cnm. 
981

[23] F. Lai and F. Kulacki, "The effect of variable viscosity on convective heat transfer along a vertical surface in a saturated porous medium," International Journal of Heat and Mass Transfer, vol. 33, no. 5, pp. 1028-1031, 1990. doi: https://doi. org/10.1016/0017-9310(90)90084-8

[24] M. E. Ouaf, "Exact solution of thermal radiation on MHD flow over a stretching porous sheet," Applied Mathematics and Computation, vol. 170, no. 2, pp. 1117-1125, 2005. doi: https://doi.org/10.1016/j.amc.2005.01.010

[25] A. Raptis and C. Perdikis, "Thermal radiation of an optically thin gray gas," International Journal of Applied Mechanics and Engineering, vol. 8, no. 1, pp. 131-134, 2003.

[26] A. Raptis, "Free convective oscillatory flow and mass transfer past a porous plate in the presence of radiation for an optically thin fluid," Thermal Science, vol. 15, no. 3, pp. 849-857, 2011. doi: https://doi.org/10.2298/tsci101208032r

[27] I. Hassanien, "The effect of variable viscosity on flow and heat transfer on a continuous stretching surface," Journal of Applied Mathematics and Mechanics, vol. 77, no. 11, pp. 876-880, 1997. doi: https://doi.org/10.1016/0020-7225(92) 90115-w

[28] N. Kafoussias and E. Tzirtzilakis, "Biomagnetic fluid flow over a stretching sheet with non linear temperature dependent magnetization," Zeitschrift Für angewandte Mathematik und Physik, vol. 54, no. 4, pp. 551-565, 2003. doi: https://doi.org/10.1007/s00033-003-1100-5

[29] E. Tzirtzilakis and G. Tanoudis, "Numerical study of biomagnetic fluid flow over a stretching sheet with heat transfer," International Journal of Numerical Methods for Heat \& Fluid Flow, vol. 13, no. 7, pp. 830-848, 2003. doi: https://doi. org/10.1108/09615530310502055

[30] V. Nikiforov, "Magnetic induction hyperthermia," Russian Physics Journal, vol. 50, no. 9, pp. 913-924, 2007. doi: https: //doi.org/10.1007/s11182-007-0133-1

[31] M. Murtaza, E. Tzirtzilakis, and M. Ferdows, "Three-dimensional biomagnetic flow and heat transfer over a stretching surface with variable fluid properties," in Advances in Mathematical Methods and High Performance Computing. London, UK: Springer, 2019.

[32] V. Loukopoulos and E. Tzirtzilakis, "Biomagnetic channel flow in spatially varying magnetic field," International Journal of Engineering Science, vol. 42, no. 5-6, pp. 571-590, 2004. doi: https://doi.org/10.1016/j.ijengsci.2003.07.007

[33] E. Tzirtzilakis and M. Xenos, "Biomagnetic fluid flow in a driven cavity," Meccanica, vol. 48, no. 1, pp. 187-200, 2013. doi: https://doi.org/10.1007/s11012-012-9593-7 